\title{
SOBRE ALGUMAS RELAÇÕES ENTRE QUALIFICAÇÃO, TRABALHO DOCENTE E GÊNERO
}

\author{
Sarah Jane Alves Durães*
}

\begin{abstract}
RESUMO: Este artigo, com base em uma revisão bibliográfica, apresenta uma análise da qualificação do trabalho docente como produto e produtora de uma construção social. Nessa ótica, argumenta que as condições sociais vividas pelos professores e professoras levam ao reconhecimento diferenciado do trabalho docente e que, embora a área educacional seja eminentemente feminina, ainda se reconhecem, como trabalho docente qualificado, os atributos masculinos. Além desse aspecto, argumenta que a configuração da qualificação do trabalho docente de homens e mulheres está condicionada aos processos de organização da instrução pública, aos fatores externos à escola e a experiências e saberes dos indivíduos, apropriados por eles e elas ao longo de suas vidas.
\end{abstract}

Palavras-chave: Qualificação. Trabalho docente. Gênero. Feminização do magistério.

\section{SOME RELATIONS BETWEEN SKILL, TEACHING WORK AND GENDER}

ABSTRACT: This text, by bibliographic revision, presents an analyzes about skill of teacher's work as a producer and product of social construction. In addition, it discusses the social condition which had been experienced by male and female teachers resulting in different recognitions of male and female teachers' skills. Moreover, the skill of male and female teachers has been conditioned by the processes of public instruction organization, the external factors of the school and the experiences and knowledge of the individuals, which had been acquired by them throughout their lives.

Key words: Skill. Teacher work. Gender. Feminization of teaching.

Doutora em Educação pela Pontifícia Universidade Católica de São Paulo (PUC-SP) e professora do Departamento de Educação e do Programa de Pós-Graduação em Desenvolvimento Social da Universidade Estadual de Montes Claros.E-mail: sj-duraes@uol.com.br 


\title{
A PROPOS DE CERTAINES RELATIONS ENTRE QUALIFICATION, TRAVAIL D'ENSEIGNEMENT ET GENRE
}

\begin{abstract}
RÉSUMÉ: Cet article, fondé sur une révision bibliographique, présente une analyse de la qualification du travail d'enseignement comme produit et producteur d'une construction sociale. Dans cette perspective, l'article développe l'idée que les conditions sociales vécues par les professeurs hommes et femmes conduisent à la reconnaîssance différenciée du travail d'enseignement et que, bien que le domaine éducationnel soit éminemment féminin, on reconnaît encore, comme travail d'enseignement qualifié, les attributs masculins. Outre cet aspect, l'article montre que la configuration de la qualification du travail d'enseignement des hommes et femmes est conditionnée par les processus d'organisation de l'instruction publique, par les facteurs externes à l'école et aux expériences et savoirs des individus, hommes et femmes, appropriés par ceux-ci et celles-ci tout au long de leur vie.

Mots-clés: Qualification. Travail d'enseignement. Genre. Féminisation du magistère.
\end{abstract}

\section{Introdução}

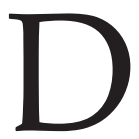

iferentes pesquisas têm priorizado a análise do trabalho docente. Algumas apontam os efeitos das políticas públicas no processo de profissionalização docente, outras se restringem à reflexão sobre os institutos formadores. Existem também aquelas que versam sobre a história do trabalho docente ou, ainda, que privilegiam o estudo dos fatores que contribuíram para que o magistério, e, em específico, o das séries iniciais, se tornasse eminentemente um gueto feminino.

Ao encontro dessas discussões, neste artigo se procura explorar algumas relações entre qualificação, trabalho docente e gênero. Inicialmente, serão comentadas algumas vertentes presentes na Sociologia do Trabalho que dimensionam os usos da categoria qualificação. Em seguida, passa-se a uma análise da qualificação do trabalho docente. Para tanto, foram consideradas duas premissas não excludentes: a primeira, alguns aspectos econômicos e culturais que foram constitutivos da história do trabalho docente, e, a segunda, a organização do espaço escolar como trabalho feminino e trabalho de mulher. Por fim, serão comentados alguns fatores que proporcionaram o processo de feminização do magistério e como este favoreceu a alteração da qualificação do trabalho docente, com especial atenção à qualificação no setor público.

\section{A qualificação como construção social}

Na literatura referente à Sociologia do Trabalho, o conceito de qualificação encerra em si perspectivas polêmicas e contraditórias. Assim, como campo teórico e analítico, esse conceito não é consensual (Villavicencio, 1992; Castro, 1993; 
Ferreti, 1993; Posthuma \& Leite, 1995). Com efeito, é possível identificar três principais usos analíticos de qualificação: ora relacionada ao posto de trabalho, ${ }_{1}$ ora ao(à) trabalhador $(a){ }^{2}$ ora, ainda, à construção social. Esta última é a dimensão que será priorizada neste artigo.

Autoras como Posthuma e Leite (1995) e Segnini (2000), por exemplo, têm utilizado o conceito de qualificação como construção social, justificando, assim, que é possível uma análise mais ampla das relações entre trabalho e gênero. ${ }^{3}$ Entretanto, vale ressaltar que a dificuldade já fora alertada por Posthuma e Leite (1995). Essa perspectiva analítica, segundo as pesquisadoras, é de difícil operacionalização porque passa a ser reconhecida como síntese de múltiplas determinações e, por isso, em constante modificação. A qualificação como construção social não é vista como um conceito estático, mas como uma perspectiva heurística - que fomenta pesquisa. Nesse caso, pressupõe, no atual momento, também um conceito em construção.

Entretanto, esse conceito veio romper com uma e outra perspectivas, ou seja, com a qualificação relacionada ao trabalhador ou ao posto de trabalho. Por isso é possível afirmar que esse conceito é, ao mesmo tempo, sintetizador e diferenciado. Como síntese, dimensiona a qualificação como alocada tanto no posto de trabalho quanto no trabalhador. E, além dos aspectos tradicionalmente considerados,

(...) na construção social da qualificação jogam papel importante não apenas os aspectos técnicos, mas os aspectos de personalidade e os atributos do trabalhador (como condição étnica, de gênero, generacional). Estes são amplamente variáveis segundo o tipo e a situação de trabalho; são também diferencialmente valorizáveis segundo o contexto societal, as condições conjunturais (da economia, da política e da cultura) e a experiência histórica dos distintos grupos profissionais. (Castro, 1992, p. 82)

Para Segnini (2000, p. 20), a qualificação deve ser entendida para além dos processos de escolarização e formação profissional, devendo ser reconhecida como resultado

(...) de uma relação social (de classe, de gênero, de etnia, generacional) que se estabelece nos processos produtivos, no interior de uma sociedade regida pelo valor de troca e fortemente marcada por valores culturais que possibilitam a construção de preconceitos e desigualdades. Isso quer dizer que os conhecimentos adquiridos pelo trabalhador por meio de diferentes processos e instituições sociais - família, escola, empresa, etc... - somados às suas habilidades, também adquiridas socialmente, acrescidas de suas características pessoais e de sua subjetividade, de sua visão de mundo, constituem um conjunto de saberes e habilidades que significa, para ele, trabalhador, valor de uso.

Em decorrência dos elementos culturais, políticos e econômicos, a qualificação pode se manifestar, de forma diversa, entre trabalhadores, entre gerências, entre os 
sujeitos e grupos internos e externos à fábrica. Ela passa a ser vista como resultado de um conjunto de relações sociais.

Assim sendo, para compreender os atributos do indivíduo (como construção social) deve-se levar em conta a história de vida dos(as) trabalhadores(as) e, na mesma direção, a história de construção dos atributos de que eles são portadores. $\mathrm{O}(\mathrm{A})$ trabalhador(a) é uma pessoa; e uma parte importante da pessoa é o(a) trabalhador(a), uma vez que é impossível separar o eu profissional do eu pessoal. Quando se tomam como análise as trajetórias de vida dos(as) trabalhadores(as), identifica-se uma diferenciação nas formas de aquisição de experiências e saberes, nos processos de escolarização e de profissionalização decorrentes das relações de classe, gênero e raça. ${ }^{4}$

Outra dimensão a considerar na qualificação como construção social diz respeito ao reconhecimento dos saberes tácitos. Em oposição aos saberes formais, esses saberes tendem a ser de propriedades individuais e, por isso, não estão disponíveis nem para a empresa, nem para os(as) trabalhadores(as). Tal constatação foi estabelecida por Rizek e Leite (1998) por meio de depoimentos de mulheres que trabalhavam em um subsetor de perfumaria e sabões. As pesquisadoras identificaram uma tendência à ausência de códigos verbais para a descrição de postos e tarefas e, sobretudo, de tratamento, quer expresso pelas trabalhadoras, quer pela empresa, por considerar certos saberes inerentes às sensibilidades corporais e, por isso, naturais. São considerados desprovidos de historicidade e de qualificação. Não somente as mulheres, mas também os homens tendem a associar o desempenho dessas funções àquelas realizadas diferentemente pelos sexos nas esferas privadas. ${ }^{5}$

Ademais, cumpre ressaltar, ainda, que, em certas situações, esses saberes podem também ser traduzidos em estratégias de resistência dos trabalhadores e trabalhadoras à organização do trabalho a que eles ou elas estejam submetidos. Como saberes tácitos, podem ser utilizados, consciente ou inconscientemente, individual ou coletivamente, como mecanismo para romper com as formas de controle presentes na organização capitalista (Neves, 1994).

Em resumo, as qualificações tácitas apresentam três dimensões. São elas as “(...) relacionadas com a prática de tarefas que envolvem ações repetidas (...)"; a segunda "(...) reside no fato de que existem diferentes graus na tomada de consciência conforme a tarefa a ser realizada exija um grau mais intenso ou menos intenso de consciência de ação (...)"; e a última “(...) refere-se à natureza coletiva do processo de trabalho e a uma necessidade que os trabalhadores têm, vale dizer, a necessidade de desenvolver qualificações de cooperação" (Jones \& Wood, 1984, p. 9-11).

Enquanto o processo taylorista ${ }^{6}$ e, por extensão, a tese bravermaniana ${ }^{7}$ consideram os saberes tácitos como saberes inadequados ao processo de trabalho, para o reconhecimento da construção social da qualificação, esses saberes ganham 
novo e valorado status, ressaltando-se, inclusive, a subjetividade e a produção coletiva dos(as) trabalhadores(as). Essa nova possibilidade de análise se diferencia do modelo anterior porque o(a) trabalhador(a), em relação ao coletivo, passa a ser reconhecido(a) pelos diferentes processos que participaram e participam do saber-ser e saber-fazer do(a) trabalhador(a). Vários elementos são considerados constitutivos da valorização ou da desvalorização do seu trabalho.

Neste sentido, acrescenta-se que a qualificação - na perspectiva da construção social - passa a ser reconhecida não somente pela base técnico-científica do processo de trabalho, mas também, em especial, passa a ser considerada resultante das relações sociais estabelecidas entre pessoas portadoras de distintas trajetórias e características. Assim, nas condições de gênero, como o trabalho realizado por homem ou mulher é diferentemente reconhecido entre grupos e sociedades, dependendo dos sujeitos e das relações em jogo, o trabalho será mais ou menos valorizado. O que significa que

(...) assim como uma tecnologia mais produtiva desvaloriza correspondentemente os elementos produzidos pelas tecnologias menos produtivas, uma geração capaz de trabalho mais complexo, quando ingressa no mercado de trabalho, desvaloriza a que imediatamente antecede, assim como todas as anteriores, que passam a ser comparativamente menos qualificadas. (Bruno, 1996, p. 111)

Dado esse fato, estabelece-se uma hierarquia, um reconhecimento diferenciado do trabalho. Nas palavras de Bruno (1996, p. 111), “(...) é exatamente a existência de hierarquizações múltiplas entre os elementos da qualificação que confere ao termo tantos significados distintos".

Outro elemento que deve ser analisado com referência à qualificação diz respeito às trajetórias profissional e de vida, uma vez que certas experiências ou disposições requeridas para a realização do trabalho não estão diretamente relacionadas somente à formação profissional e/ou escolar. As trajetórias de vida de homens e mulheres configuram um campo de possibilidades que tendem a demarcar os espaços de inclusão/exclusão no mundo do trabalho. Por isso, “(...) trata-se, a nosso ver, de uma dimensão que configura, dentro da fábrica, uma imagem e um lugar do feminino gerado e reproduzido dentro e fora das fábricas" (Rizek \& Leite, 1998, p. 80). Vale ressaltar que certos atributos exigidos pelo capitalismo, como mencionados anteriormente, fazem parte dos saberes construídos na esfera privada e no espaço doméstico. $^{8}$

Retomando a observação de Rizek e Leite, conclui-se que só se deve comparar a qualificação entre trabalhadores(as) quando eles(as) possuírem os mesmos elementos - mesma situação econômica e base tecnológica - e demais experiências semelhantes advindas das condições de geração e gênero, por exemplo. Além de 
tomar como referência a base tecnológica, a qualificação está diretamente relacionada às formas pelas quais a atividade exercida é reconhecida na sociedade.

Nessas circunstâncias, o valor social do trabalho estará condicionado, por exemplo, às características do sujeito (escolarização, gênero, raça, idade e outros); do posto de trabalho (os saberes inscritos na tecnologia, os componentes intelectual e manual); das lutas que são estabelecidas pelos sujeitos - entre trabalhadores(as), entre trabalhadores(as) e gerência, trabalhadores(as) e sindicato e outros -; da configuração da remuneração e da profissão. Nesse caso, a análise da qualificação pressupõe conflitos e contradições entre diferentes elementos. Isso significa dizer que

(...) a qualificação depende, neste sentido, de novos e importantes fatores que deságuam em duas linhas: por um lado, o costume e a tradição socialmente construída; por outro, a organização coletiva que sustenta definições - a um só tempo defensivas e ofensivas - que protegem corporações, ou coletivos autoidentificados por direitos e trajetórias profissionais, quaisquer que sejam eles. (Castro, 1992, p. 80)

Além de agregar os aspectos já mencionados até então, quer relacionados ao posto de trabalho, quer ao(à) trabalhador(a), a qualificação, como construção social, incorpora mais alguns outros. Em especial, tal perspectiva conduz a redefinir a concepção de coletivo e a refletir sobre os distintos grupos que ocupam o chão da fábrica.

Acerca disso, Castro (1991) propõe que o coletivo de trabalhadores seja reconhecido como coletivos e resultantes de relações dentro e fora da fábrica. A autora aprofunda a análise a partir da perspectiva política colocada por Burawoy, quando ele distingue relações sociais na produção, ou seja, "(...) às relações sociais estabelecidas no âmbito do processo de trabalho e ligadas à divisão técnica do trabalho $(. . .)^{\prime \prime}$, e relações sociais da produção que são "(...) as relações que têm a ver com a distribuição e o consumo da mais-valia, sustentadas nas relações de propriedade (...)" (Castro, 1991, p. 45-46).

Em decorrência, o debate passa a incluir outras esferas: a da educação e a do trabalho realizado por homens e mulheres nos espaços privados (incluem-se, principalmente, aqueles presentes na instituição familiar), das organizações institucionais e sindicais, além das relações sociais $d a, n a$ e fora da fábrica. Isso quer dizer que a vida do(a) trabalhador(a) é vivida também além das relações da fábrica e, por isso, pressupõe outros espaços de qualificação e, concomitantes, campos de conflito.

\section{Qualificação e trabalho docente}

Embora este estudo se tenha centrado na perspectiva analítica presente na Sociologia do Trabalho e tecida nas relações produtivas capitalistas, não se pretende, 
aqui, realizar uma transposição mecânica para a análise da qualificação do trabalho docente. Isso, principalmente, se deve ao reconhecimento das limitações da sua utilização no campo educacional. Dito de outra forma, é claro que não se pode pensar adequadamente em qualificação sem considerar as similaridades existentes entre a organização do trabalho na escola e o trabalho na fábrica, já que ambos estão inseridos em uma sociedade capitalista. Contudo, faz-se necessário estabelecer as diferenças entre os elementos que estão inseridos em uma e outra organização.

Isso posto, quanto à história de configuração do trabalho docente, debate-se a seguinte questão: esse trabalho é ou não reconhecido como profissão. Em sua dissertação de mestrado, Fidalgo (1993), além de sintetizar essa polêmica apresentando-a a partir de três correntes explicativas, identificou aspectos divergentes e convergentes entre elas. A primeira corrente, à qual será dedicada especial atenção neste artigo, parte em defesa de um processo de profissionalização do trabalho docente. Há outra que argumenta em favor da existência de um processo de proletarização do trabalho docente. ${ }^{9}$ E, por último, a terceira corrente aponta a existência de ambiguidade no trabalho docente. ${ }^{10}$

Em direção à análise dos conceitos de profissão, ressalta-se que, embora este termo tenha a mesma origem que ofício, a profissão “(...) emerge quando um número definido de pessoas começa a praticar uma técnica definida, baseada numa formação especializada (...)” e quando “(...) representa a fusão da eficácia econômica e da legitimidade cultural” (Dubar, 1997, p. 128). Além destas definições, é possível estabelecer diferenciação entre profissão e ofício pensando em

(...) um conjunto de distinções socialmente estruturantes e classificadoras que se reproduziram através dos séculos: cabeça/mãos, intelectuais/manuais, alto/baixo, nobre/ vilão, etc. Acontece ainda que ofícios e profissionais participam do mesmo modelo de origem: as corporações, isto é, corpos, confrarias, e comunidades no seio das quais os membros estavam unidos por laços morais e por um respeito às regulamentações pormenorizadas dos seus estatutos, constituem estados reconhecidos pelo Poder Real. (Dubar, 1997, p. 124; grifos do autor)

Em síntese, para a configuração do processo de profissionalização, é necessária a presença de três aspectos, quais sejam:

(...) especialização dos serviços que permite aumentar a satisfação de uma clientela (...);

(...) criação de associações profissionais que obtêm para os seus membros a proteção exclusiva dos clientes e dos empregadores que requerem o serviço do seu ofício e colocam uma linha de separação entre eles e as pessoas não qualificadas que permite aumentar o prestígio do ofício (...); e, por último, (...) de constituição de uma formação específica assente num corpo sistemático de teoria que permite a aquisição de uma cultura profissional (...). (Dubar, 1997, p. 128; grifos do autor) 
Enguita (1991), quando discorreu sobre as características da história do trabalho docente na Espanha, a partir do século XIX, assinalou que o termo profissionalização está intimamente relacionado à posição social e ocupacional dos professores. Em outras palavras, à inserção e ao prestígio que o grupo de professores exerce dentro de uma certa comunidade. Ele estabeleceu cinco critérios para a definição do docente como profissional: competência, vocação, licença, independência e autorregulação.

A competência diz respeito à formação específica e esta só poderá ser julgada por aqueles que partilham da mesma profissão. No que se aplica à docência, embora o conhecimento técnico seja reconhecido, quaisquer pessoas podem opinar sobre ela. Por isso se descaracteriza a ideia de sagrado. Vocação, aqui, é entendida como um apelo ou chamado e evoca um aspecto religioso. Nesse caso, a profissão caracteriza-se como atividade prestada à humanidade e, por isso, não carece ser remunerada. Quanto à licença, os professores valem-se daquilo que é reconhecido e protegido pelo Estado. Quanto à independência dos docentes, à sua autonomia em relação às organizações e aos clientes, eles são parcialmente autônomos. Mesmo submetidos ao Estado, eles partilham de instâncias de colegiados, que são, em geral, também docentes.

E, por último, a autorregulação docente faz com que a identidade do(a) professor(a) e a solidariedade grupal sejam controladas por si mesmas. Nesse ponto de vista, é valiosa a observação feita por Enguita (1991, p. 46) quando diz: “(...) a categoria de docentes carece de um código ético ou deontológico (o que não significa que sejam amorais ou não possuam normas grupais informais de comportamento!) e de mecanismos próprios para julgar a seus membros ou resolver conflitos internos".

Em consonância com essa argumentação, Nóvoa (1991) analisou as mudanças transcorridas no trabalho docente em Portugal do século XIX. Nas palavras do educador português, nesse período se pode constatar, claramente, a ambiguidade do estatuto dos professores, pois se identifica

(...) uma imagem intermediária dos professores, que são vistos como indivíduos entre várias situações: não são burgueses, mas também não são povo; não devem ser intelectuais, mas têm de possuir um bom acervo de conhecimentos; não são notáveis locais, mas têm uma influência importante nas comunidades; devem manter relações com todos os grupos sociais, mas sem privilegiar nenhum deles; não podem ter uma vida miserável, mas devem evitar toda a ostentação; não exercem o seu trabalho com independência, mas é útil que usufruam de alguma autonomia; etc. Estas perplexidades se acentuam com a feminização do professorado, fenômeno que se torna bem visível na virada do século e que introduz um novo dilema entre as imagens masculinas e femininas da profissão. (Nóvoa, 1991, p. 13)

Também apresentando o trabalho docente como cambiante, Ozga e Lawn (1991) alertaram sobre a necessidade de reconhecê-lo como resultante de uma 
construção social. Dirigindo-se a algumas críticas acerca da utilização bravermaniana de qualificação do trabalho docente, afirmaram que, por essa abordagem ser a-histórica e mecanicista, conduziu à homogeneização de níveis, áreas e tipos de trabalho. E, então, concluem que Braverman deixou de considerar "(...) uma grande variedade tanto de formas de trabalho quanto de formas de controle do trabalho" (Ozga \& Lawn, 1991, p. 149).

Além dessas considerações sobre o que se pode configurar como profissionalização, Dubar (1997, p. 127) chamou a atenção para a explicação dada por Max Weber. Segundo ele, para Weber, a profissionalização consiste em um dos processos essenciais da modernização da sociedade, o que significou mudança de uma socialização primária, comunitária para a realização de tarefas racionais que implicam competência e especialização.

Quando se tem em vista a descrição dos processos que participam da profissionalização, o conceito de carreira é de substancial importância para que se possa entender quais elementos dificultam ou favorecem a trajetória de professores e professoras. Desse modo, para analisar os elementos que favorecem a carreira masculina, em especial, é essencial identificar aqueles que dificultam a ascensão das mulheres no mundo do trabalho (docente).

O conceito de carreira apresenta vantagens diversas quanto à análise do trabalho docente porque

(...) em primeiro lugar, permite comparar as pessoas no exercício de diferentes profissões. Depois, é mais focalizado, mais restrito que o estudo da vida de uma série de indivíduos. Por outro lado, e isso é importante, comporta uma abordagem a um tempo psicológica e sociológica. Trata-se, com efeito, de estudar o percurso de uma pessoa numa organização (ou numa série de organizações) e bem assim de compreender como as características dessa pessoa exercem influência sobre a organização e são, ao mesmo tempo, influenciadas por ela. (Huberman, 1995, p. 38; grifo do autor)

Com relação ao processo segundo o qual se constrói a carreira das(os) professoras(es) das primeiras séries, também Gonçalves (1995, p. 145) estabeleceu “(...) dois os pontos de análise, distintos, mas complementares, sob que pode ser estudado o percurso profissional docente: o desenvolvimento profissional, em termos gerais, e o da construção da identidade profissional". Segundo ele, o primeiro pressupõe o desenvolvimento pessoal, a profissionalização e a socialização (que implica socialização profissional ou socialização do professor); o segundo, o da construção da identidade profissional, pressupõe a construção de representações fundadas em quatro aspectos do trabalho docente, quais sejam:

(...) o capital de saberes, saberes-fazer e saberes-ser que fundamentam a prática; as condições do exercício dessa mesma prática, no que respeita tanto à sua autonomia e controle 
como às do contexto em que ela se desenrola; a sua pertinência cultural e social e, por último, as questões de estatuto profissional e prestígio social da função docente. (Gonçalves, 1995, p. 145-146)

No que se refere à análise da qualificação do trabalho docente, acredita-se ser a dimensão do saber um dos pontos de estrangulamento. Primeiro, dada a especificidade do trabalho docente e da sua diferenciação com o trabalho no processo fabril. E, depois, porque, para o trabalho docente e para a análise de sua qualificação como construção social, faz-se necessário reconhecer a importância dos saberes tácitos dos diferentes sujeitos que deles participam. Por último, e em decorrência desse reconhecimento, sendo o magistério primário composto majoritariamente por mulheres, conduz à identificação de características da qualificação, inerentes às práticas sociais das quais elas fazem parte.

Tardif (1992), tendo em vista a compreensão da natureza dos saberes advindos das experiências dos professores, afirmou serem eles que servem como fundamentos para a competência profissional, embora eles sejam de natureza diferente daqueles saberes formais ou acadêmicos transmitidos pelas instituições responsáveis pela formação. O seu esforço foi mostrar que o saber da experiência não decorre das qualidades ocultas, mas é resultante dos processos vividos pelos professores no processo de ensino, denominados por ele condições objetivas. No seu ponto de vista, elas, as condições objetivas,

(...) correspondem ao contexto segundo o qual se desenrola o trabalho de ensino e sua execução sobre diversos atos profissionais constitutivos da prática cotidiana. A análise das condições permite uma melhor compreensão por que o saber da experiência escapa ao processo de produção dos saberes em vigor sobre o campo de pesquisa e da pedagogia universitária. (Tardif, 1992, p. 3-4)

As condições objetivas atuam diferencialmente sobre os atributos subjetivos do sujeito como, por exemplo, a personalidade e o estilo de ensino. Nesse caso, a natureza do saber estará diretamente relacionada aos modelos organizacionais e aos sujeitos que estão inseridos neles. O saber instrumental, que é a base no trabalho fabril, traz alguns problemas ao trabalho docente. Além de desvalorizar a experiência prática e seus saberes, ele escamoteia a interação entre professor e aluno. Para analisar a questão do saber docente, Tardif (1992, p. 16) estabeleceu uma diferenciação entre saber formal e saber prático. Os saberes formais representam o domínio dos objetos do conhecimento, sendo de caráter cognitivo - por exemplo, a formalização -, ao passo que os saberes práticos envolvem características não cognitivas - contingências, noção de tempo, capacidade de decisão nas situações e outras.

Em se tratando do saber docente, este é resultado de diferentes tipos de saberes: derivados do conhecimento científico, da cultura escolar, da capacidade 
inventiva dos professores de atuarem mediante contingências. Os saberes formais, decorrentes das ciências da educação e das instituições formadoras, não são suficientes para o exercício da profissão docente. Basta lembrar que os professores atuam sobre seres humanos (Tardif, 1992, p. 22).

Acrescenta-se, ainda, a propósito do saber docente, que os professores e professoras têm demonstrado que existe uma tendência de eles e elas repetirem, nas práticas de ensino, as suas experiências educacionais familiares e pessoais. Embora o saber docente advenha de um campo profissional institucionalizado, encontramse presentes, nas relações sociais, as marcas das contingências. Assim, por conseguinte, os saberes docentes não se derivam necessariamente do modelo racional e burocrático da sociedade moderna e do Estado, mas pressupõem, igualmente, formas de ação fundadas em tradições, costumes, rotinas e hábitos da ação educativa e pedagógica. Em razão dessa interação entre os sujeitos que participam da escola, os saberes são interativos e por isso, substancialmente, diferem o trabalho docente do trabalho realizado sobre artefatos e técnicas (Tardif, 1992).

\section{Trabalho docente, gênero e qualificação}

A análise do processo de feminização do magistério tem sido um forte eixo analítico em torno da díade trabalho docente e gênero. Estudos têm demonstrado que o trabalho docente, em especial o do ensino primário, já foi muito exercido por homens, entretanto, mais precisamente a partir do século XIX, eles têm se evadido e, cada vez mais, as mulheres têm ocupado esse espaço. Desde então, a educação tem sido uma carreira feminina e, ainda hoje, tende a ser, basicamente, um trabalho de mulher (Enguita, 1991; Apple, 1987, 1988, 1995; Lopes, 1991; Chamon, 1996; Louro, 1997). Assim sendo, tem ocorrido um processo de feminização do magistério. E, segundo Enguita (1991, p. 52), “(...) o termo feminização não só expressa um ponto de chegada, como também e fundamentalmente um processo". Posto que a ocorrência da feminização é reconhecida como processo, pode-se afirmar que tal processo não tem ponto de partida predeterminado nem de chegada.

Vale lembrar que há, na literatura educacional, confirmações da ocorrência de processo de feminização em certos países, por exemplo na Inglaterra e no País de Gales, nos Estados Unidos, na Espanha, em Portugal e no Brasil. Tal processo se manifestou em ritmos diferentes e com as respectivas peculiaridades, próprias das condições históricas nas quais se encontravam os países (cf. Apple, 1987, 1988, 1995; Enguita, 1991).

Para entender esse processo, torna-se necessário analisar tanto a dinâmica de classe quanto a de gênero. Aliás, segundo Apple (1995, p. 56), “(...) a atividade 
docente foi progressivamente passando de trabalho de homem a trabalho de mulher $(\ldots)$ ", e mais ainda, “(...) é preciso verificar como se deu essa mudança e as condições econômicas e de gênero em torno disso (...)". Em conclusão, a feminização do magistério consolidou-se porque os homens o abandonaram em decorrência da sua desvalorização. Na visão do autor, “(...) os homens começaram a - e quase sempre conseguiram - procurar trabalho em outro lugar" (Apple, 1995, p. 59). O autor em pauta argumentara que, assim como o trabalho docente, outras ocupações passaram por um processo de feminização. Então, igualmente ao trabalho em escritório,

(...) o magistério era uma ocupação masculina no século XIX e passou a feminina no século XX. (...) Essa transformação está ligada, de uma forma complexa, a alterações nas relações patriarcais e econômicas que vinham reestruturando a sociedade mais ampla. (Idem, ibid., p. 56)

Justificando a ocorrência desse processo, Enguita (1991) apresenta quatro motivos. Primeiramente porque a carreira do magistério tem sido considerada uma atividade extradoméstica e representa uma preparação para o exercício da maternidade; desse modo, é uma atividade transitória. Em decorrência, a carreira do magistério tem proporcionado perda de prestígio. Em segundo lugar, os baixos salários têm afugentado, progressivamente, os homens, que têm procurado outros setores da economia como: a indústria, o comércio e a administração pública.

Outro aspecto se refere à tentativa de grupos dominantes utilizarem os docentes para transmitirem sua cultura e manter a ordem. Nesse caso, as mulheres são socialmente "(...) consideradas mais conservadoras, menos ativas e mais dispostas a aceitar a autoridade e a hierarquia que os homens" (Enguita, 1991, p. 52). Finalmente, a escola pública é um dos poucos setores em que homens e mulheres tendem a receber o mesmo salário.

Embora prevaleça, no serviço público, o princípio da universalidade - a qualquer cidadão, homem ou mulher, os mesmos critérios de seleção para que eles e elas possam competir em condições de igualdade -, ainda se identifica, nesse setor, a formação de guetos sexuais.

Uma das justificativas para tal é que alguns critérios existentes nos processos de seleção/admissão das instituições públicas tendem a reforçar mais ou menos a vinculação entre os postos de trabalho e alguns atributos masculinos ou femininos. $\mathrm{E}$, com base nesse fato, homens e mulheres geralmente se inscrevem nos postos de trabalho de acordo com as designações socialmente mais apropriadas com relação ao sexo do candidato.

Além disso, o processo seletivo do concurso apenas ratifica uma divisão sexual do trabalho, divisão essa vivenciada no transcurso das trajetórias escolares e 
de vida nas quais está demarcado, diferentemente, o campo de possibilidades para homens e mulheres. Em síntese, a discriminação entre os sexos, embora presente no interior das instituições e reforçada por elas, pode ser caracterizada como anterior ao processo de seleção/admissão.

Lembrando Ozga e Lawn (1991), a concepção de qualificação do trabalho docente que vigora (ainda!) é masculina. Também Williams (1995) argumentou que a sociedade tende a diferenciar os talentos da qualificação e que existe uma tendência à reprodução da hierarquia de gênero. Isso leva a pensar que

(...) o local de trabalho é o lugar central para a criação e a reprodução das diferenças e desigualdades de gênero. Tanto homens como mulheres são forçados a agirem de acordo com certas formas determinadas pelas hierarquias organizacionais, descrição do emprego e práticas informais presentes no local do trabalho, as quais são baseadas profundamente em concepções de masculinidade e feminilidade, mas esta construção social do gênero favorece homens recompensando-os pelas qualidades "masculinas" que eles trazem com eles para o local de trabalho. (Williams, 1995, p. 15, grifo da autora)

Especialmente em certas profissões consideradas trabalho de mulher, como a enfermagem e a educação, por exemplo, as mulheres são compelidas a acreditar nas suas características femininas e a justificar as suas oportunidades profissionais como decorrentes dessas diferenças.

A interpretação desses aspectos, sob a ótica do processo de qualificação, tende a relacionar-se sobretudo com os trabalhadores do sexo masculino, naqueles contextos que têm sido ou foram tradicionalmente ocupados por eles. Vale lembrar que os parâmetros para a definição sobre se o trabalhador é ou não qualificado remetem às características das atividades executadas por homens ou pertencentes ao universo masculino. Na interpretação de Williams (1995), embora a área educacional seja eminentemente feminina, ainda se reconhecem, como trabalho docente qualificado, os atributos masculinos.

Dito isso, cabe salientar que a qualificação exigida para o trabalho docente, na sociedade capitalista, centraliza-se na base tecnológica, no controle e na racionalização das atividades. Cultural e socialmente, esses aspectos são reconhecidos como atributos masculinos e, por sua vez, são aqueles que dimensionam o trabalho qualificado na produção capitalista. Em direção contrária, as características de cuidado, carinho, zelo e exercício de atividades de coordenação motora fina são consideradas inerentes ou inatas à mulher, em vez de considerá-las como constituídas em espaços anteriores e/ou externos ao local de trabalho e em cursos de formação de trabalhadoras (embora os cursos de formação/treinamento as reforcem). Não sendo reconhecidas como advindas de processos de escolarização/formação, essas características tendem a ser desvalorizadas. E, principalmente, elas são desvalorizadas por ter sido geradas 
de outras relações e, em especial, constituídas no espaço privado e doméstico. Daí alguns fatores relativos aos atributos das mulheres não serem reconhecidos como qualificantes.

Em síntese, os critérios que estão postos para a identificação do trabalho docente qualificado são determinados pelo universo masculino. A sociedade tende a reconhecer o trabalho feminino, em especial aquele realizado na esfera doméstica, decorrente do âmbito da natureza, das condições inatas e do talento. Em outras palavras, a mulher-professora é portadora de talentos e o homem-professor, de qualificação.

\section{Algumas considerações finais}

A análise sobre a qualificação do(a) trabalhador(a) no mundo do trabalho capitalista só tem sentido se extrapolar as relações da/na produção, ou seja, relacioná-la com os aspectos culturais e políticos das relações sociais mais amplas. Em se tratando de gênero, objeto deste estudo, cabe reconstituir a história do trabalho de homens e mulheres, suas trajetórias de vida - desde as relações domésticas e privadas até a influência delas na esfera produtiva. Portanto, é importante investigar a qualificação do(a) trabalhador(a) não apenas pela ótica de quem o(a) recruta, mas também como cada um a representa e a vivencia.

Quanto ao trabalho docente, embora ele tenha se tornado eminentemente um trabalho de mulheres, a concepção de qualificação que passou a vigorar ratificava que essa área profissional ainda é um espaço de exercício do poder masculino. Ou ainda, em outras palavras, a hierarquia de gênero que passou a existir no interior das escolas considerou a mulher portadora de talentos e o homem professor, de qualificação. Nessa ótica, as condições sociais vividas por professores e professoras levaram ao reconhecimento diferenciado do trabalho docente.

Mas não só as condições de gênero possibilitam a análise da qualificação do trabalho docente. Juntamente com elas, o processo de escolarização/publicização da escola contribuiu para o reconhecimento diferenciado do trabalho docente. Assim sendo, conclui-se que a carreira docente deve ser analisada como resultante de valores historicamente construídos nas relações vividas no interior da esfera pública, bem como nas relações sociais externas a ela.

Mesmo diante da fragilidade da dimensão analítica da qualificação como construção social aplicada ao trabalho docente, a reflexão a partir dos diferentes segmentos sociais propiciou entender os diferentes (re)arranjos de homens e mulheres trabalhadores na sociedade. E mais, principalmente, possibilitou compreender melhor as relações sociais entre os sexos ocorridas no interior das escolas. Ademais, 
as incursões em diferentes áreas de conhecimento possibilitam pensar que alguns fatores que se situam no âmbito das relações econômicas e socioculturais alteram as atividades docentes e o quadro institucional que as regula.

Em última análise, a configuração da qualificação do trabalho docente de homens e mulheres está condicionada aos processos de organização da instrução pública, aos fatores externos à escola e às experiências dos indivíduos. Incluem-se, aqui, os saberes tácitos e formais apropriados por eles e elas ao longo de suas vidas.

\section{Notas}

1. A qualificação relacionada ao posto de trabalho diz respeito ao conjunto de atributos, classificações e categorização demandados pelas funções. Uma vez que os atributos são dos postos de trabalho, os comportamentos exigidos encontram-se prescritos e formalizados, ou aparecem nos discursos registrados nos quadros técnicos antes mesmo da admissão do(a) trabalhador(a). Esses aspectos podem estar condicionados não somente aos conhecimentos que estão inscritos na tecnologia, mas também podem ser identificados nos postos de trabalho como exigência de atributos decorrentes das condições de gênero, raça e idade, por exemplo (Castro, 1993).

2. A definição de trabalhador(a) qualificado(a) pode ser caracterizada a partir da formação decorrente das experiências vivenciadas na trajetória de vida de cada um e/ou nos programas de treinamento desenvolvidos no local de trabalho, nas relações sociais de conflito entre pessoas/grupos diferentes, ou em instituições destinadas a tal fim. Tendo sido satisfeitos esses critérios, então os(as) trabalhadores(as) serão portadores(as) da qualificação. Por isso “(...) o indivíduo identifica e classifica os saberes que mobiliza no exercício profissional, em termos de sua natureza, origem, funcionalidade e significação para o seu desempenho" (Castro, 1993, p. 217).

3. A utilização da categoria gênero, a partir da década de 1980, deu-se por algumas razões. A primeira delas foi uma forma de escapar da concepção natural e essencialista da palavra sexo, uma vez que tal concepção encerra em si a determinação das diferenças a partir dos elementos biológicos. Uma outra razão diz respeito à tentativa de obter a legitimidade dos estudos sobre a mulher dentro da academia. E, por último, essa categoria teve como finalidade atribuir a condição relacional aos estudos sobre a mulher. Isso, segundo Scott (1995, p. 72), justifica o fato de a palavra gênero ter sido tomada de empréstimo à gramática. Nela o gênero é "compreendido como uma forma de classificar fenômenos, um sistema socialmente consensual de distinções e não uma descrição objetiva de traços inerentes".

4. Os estudos realizados por Apple (1988) e Bowles e Gintis (1990) são exemplares para ilustrar tal afirmação.

5. Vale ressaltar que certos atributos exigidos pelo capitalismo em relação às mulheres fazem parte dos saberes construídos no espaço doméstico. Daí, inclusive, o reconhecimento destes como talentos ou componentes naturais. As relações capitalistas valem-se das polarizações para o reconhecimento diferenciado do valor social das atividades realizadas por homens e mulheres. Ao encontro do que argumentou Williams (1995, p. 6), “(...) na sociologia do trabalho, gênero parece ser alguma coisa que afeta apenas a mulher e as afeta apenas negativamente".

6. O modelo de organização taylorista, que foi organizado por Frederick Winslow Taylor, em linhas gerais, correspondia a uma prescrição de princípios de organização da produção, consistindo em um sistema administrativo com sua base ancorada em preceitos científicos. Segundo Taylor (1979, p. 29), “(...) o principal objetivo da administração deve ser o de assegurar o máximo de prosperidade ao patrão e, ao mesmo tempo, o máximo de prosperidade ao empregado". E, nesse caso, a “(...) maior prosperidade decorre da maior produção possível dos homens e máquinas do estabelecimento, isto é, quando cada homem e cada máquina oferecem o melhor rendimento possível" (Taylor, 1979, p. 31). 
7. A tese de Braverman (1987) é recorrente à análise da qualificação na perspectiva do trabalhador. Foi ele um dos primeiros a registrar a polêmica em torno dessa temática. Para a tese da proletarização do trabalhador, ele comparou uma dada geração de força de trabalho no capitalismo com as demais qualificações em momentos anteriores (pré-capitalistas). Para ele, o conceito de qualificação do trabalhador “(...) está ligado tradicionalmente ao domínio do ofício - isto é, à combinação de conhecimentos de materiais e processos com as habilidades manuais exigidas para desempenho de determinado ramo da produção" (Braverman, 1987, p. 375).

8. As relações existentes entre qualificação e gênero serão discutidas quando tratar, especificamente, da qualificação do trabalho docente.

9. Apple $(1987,1995)$ é um dos grandes defensores da corrente que explica o processo de proletarização do trabalho docente. No Brasil, partilham da sua tese Arroyo (1985), Pucci, Oliveira e Sguissardi (1991). A tese da proletarização do trabalho docente aponta um incentivo do processo de feminização do magistério por parte do Estado. Esse encorajamento aconteceu como uma estratégia de obtenção de mão de obra mais barata e mais facilmente controlada por parte do processo produtivo capitalista e do Poder Público. Pucci, Oliveira e Sguissardi (1991) consideram que a categoria docente tem se aproximado dos trabalhadores no que diz respeito ao salário, às condições de trabalho e de vida; e, para a consciência de classe, a categoria tem estado unida aos trabalhadores nos movimentos de luta.

10. Como um dos representantes, Enguita (1991) dimensiona a ambiguidade da docência entre o profissionalismo e a proletarização. Segundo ele, o termo profissionalização não está relacionado ao conceito de qualificação, conhecimento ou formação, mas à posição social e ocupacional. E a proletarização do trabalho docente não deve ser associada aos processos de trabalho fabril.

\section{Referências}

APPLE, M. Relações de classe e gênero e modificações no processo do trabalho docente. Cadernos de Pesquisa, São Paulo, n. 60, p. 3-14, 1987.

APPLE, M. Ensino e trabalho feminino: uma análise comparativa da história e ideologia. Cadernos de Pesquisa, São Paulo, n. 64, p. 14-23, 1988.

APPLE, M. Trabalho docente e textos: economia política das relações de classe e de gênero em educação. Porto Alegre: Artes Médicas, 1995.

ARROYO, M. Mestre, educador, trabalhador - organização do trabalho e profissionalização. Tese (Professor Titular), Faculdade de Educação da Universidade Federal de Minas Gerais, Belo Horizonte, 1985.

BOWLES, S.; GINTIS, H. A educação como campo de contradições na reprodução da relação capital-trabalho: reflexões sobre o princípio da correspondência. Teoria $\mathcal{E}$ Educação, Porto Alegre, n. 1, p. 93-107, 1990.

BRAVERMAN, H. Trabalho e capital monopolista: a degradação do trabalho no século XX. 3. ed. Rio de Janeiro: Guanabara, 1987.

BRUNO, L. Educação, qualificação e desenvolvimento econômico. In: BRUNO, L. (Org.). Educação e trabalho no capitalismo contemporâneo. São Paulo: Atlas, 1996. p. 91-123. 
CASTRO, N. Além de Braverman, depois de Burawoy: vertentes analíticas na Sociologia do Trabalho. Revista Brasileira de Ciências Sociais, São Paulo, v. 6, n. 17, p. 44-52, out. 1991.

CASTRO, N. A organização do trabalho, qualificação e controle na indústria moderna. In: MACHADO, L.R.S. et al. Trabalho e educação. Campinas: Papirus, 1992. p. 69-86.

CASTRO, N. Qualificação: qualidades, classificações e ações. Educacão \& Sociedade, Campinas, v. 14, n. 45, p. 211-224, 1993.

CHAMON, M.L. Relaçães de gênero e a trajetória de feminização do magistério em Minas Gerais (1830-1930). 1996. Tese (Doutorado em Educação) - Faculdade de Educação, Universidade Federal de Minas Gerais, Belo Horizonte.

DUBAR, C. A socialização: construção das identidades sociais e profissionais. Porto: Porto, 1997.

ENGUITA, M. A ambiguidade da docência: entre o profissionalismo e a proletarização. Teoria \& Educação, Porto Alegre, n. 4, p. 41-61, 1991.

FERRETTI, C.J. Modernização tecnológica, qualificação e sistema público de ensino. São Paulo em Perspectiva, São Paulo, n. 7, p. 84-91, jan./mar. 1993.

FIDALGO, F. Relações sociais, corporativismo e trabalho docente. 1993. Dissertação (Mestrado em Educação) - Faculdade de Educação, Universidade Federal de Minas Gerais, Belo Horizonte.

GONÇALVES, J.A. A carreira das professoras do ensino primário. In: NÓVOA, A. (Org.). Vidas de professores. Porto: Porto, 1995. p. 141-169.

HUBERMAN, M. O ciclo de vida profissional dos professores. In: NÓVOA, A. (Org.). Vidas de professores. Porto: Porto, 1995. p. 31-61.

JONES, B.; WOOD, S. Qualifications tacites, division du travail et nouvelles technologies. Sociologie du Travail, Paris, n. 4, 1984. (tradução - mimeo.).

LOPES, A educação da mulher: a feminização do magistério. Teoria \& Educação, Porto Alegre, n. 4, p. 22-40, 1991.

LOURO, G.L. Mulheres na sala de aula. In: PRIORE, M. (Org.). História das mulheres no Brasil. São Paulo: Unesp; Contexto, 1997. p. 443-481.

NEVES, M. Trabalho e cidadania: as trabalhadoras de Contagem. Petrópolis: Vozes, 1994.

NÓVOA, A. O passado e o presente dos professores. In: NÓVOA, A. (Org.). Profissão professor. Porto: Porto, 1991. p. 9-32. 
OZGA, J.; LAWN, M. O trabalho docente: interpretando o processo de trabalho do ensino. Teoria \& Educação, Porto Alegre, n. 4, p. 140-158, 1991.

POSTHUMA, A.C.; LEITE, M.P. Reestruturação produtiva e qualificação: reflexões sobre a experiência brasileira. In: ENCONTRO NACIONAL DA ASSOCIAÇÃO BRASILEIRA DE ESTUDOS DO TRABALHO, 4., 1995, São Paulo. Anais... São Paulo, 1995.

PUCCI, B.; OLIVEIRA, N.; SGUISSARDI, V. O processo de trabalhadores em educação. Teoria \& Educação, Porto Alegre, n. 4, p. 91-108, 1991.

RIZEK, C.S.; LEITE, M.P. Dimensões e representações do trabalho fabril feminino. In: ABRAMO, L.; ABREU, A.R.P. (Org.). Gênero e trabalho na sociologia latino-americana. São Paulo: Alast, 1998. p. 63-82.

SCOTT, J. Gênero: uma categoria útil de análise histórica. Educação \& Realidade, Porto Alegre, v. 20, n. 2, p. 71-99, jul./dez. 1995.

SEGNINI, L. Educação, trabalho e desenvolvimento: uma complexa relação. São Paulo: Unicamp, 2000. (mimeo.).

TARDIF, M. Savoirs et expèrience chez les enseignants de métier. Trabalho apresentado no Symposium du RÉF, Sherbrooke, 1992. (mimeo.).

TAYLOR, F.W. Princípios da administração científica. 7. ed. São Paulo: Atlas, 1979.

VILLAVICENCIO, D. Por una definición de la cualificación de trabajadores. Trabalho apresentado no 4. Congreso Español de Sociología, Madrid, 1992. (mimeo.).

WILLIAMS, C. Still a man's world: men who do "woman's work". London: University of California, 1995.

Recebido em 20 de junho de 2010.

Aprovado em 25 de março de 2011. 